\title{
VIABLE SYSTEM ARCHITECTURE APPLIED TO MAINTENANCE 4.0
}

\author{
Rafael Albuquerque Câmara ${ }^{1}$, Henrique São Mamede ${ }^{2}$ and Vitor Duarte dos Santos ${ }^{3}$ \\ ${ }^{1}$ Universidade Aberta, 1269-001 Lisboa, Portugal \\ ${ }^{2}$ Universidade Aberta, INESC TEC, 1269-001 Lisboa, Portugal \\ ${ }^{3}$ Universidade Nova - IMS, 1070-312 Lisboa, Portugal
}

\begin{abstract}
Disruptive requirements that currently drive the so-called Industry 4.0 (I4.0) are increasingly present in today's industries, where factories are forced to innovate in search of improvement in the quality of manufacturing of products aligned with the reductions of: manufacturing time, environmental and cost impacts with the manufacturing process. For this, an Information Systems (IS) architecture is proposed to reduce the negative impacts on an industrial operation caused by manual configuration failures in manufacturing systems, machines that are worn out in the production process and unstable integrations between industrial subsystems. The suggested SI model uses the Viable Systems Model adapted to Maintenance 4.0 technologies (Cyber-physical Systems (CPS), Manufacturing Execution Systems (MES), Data Mining and Digital Manufacturing concepts/technologies) with the goal to create an automatic purchase flow to replace parts by mitigating impending failures in industrial equipment through data mining and predictive analysis.
\end{abstract}

\section{KEYWORDS}

Maintenance 4.0, Viable Systems Model, Cyber-Physical Systems, Manufacturing Execution Systems (MES), Digital Manufacturing, Data Mining

\section{INTRODUCTION}

The current industrial sector undergoes constant changes and process updates at a speed synchronized with business models never seen before, whose production process is sequential, fault-oriented and did not require changes to succeed in manufacturing. Currently, this monolithic model no longer supports dynamic markets in the face of the integration and speed necessary to the customer, supplier and production to stay competitive in the world market. In this scenario, industrial production needs to be continuously synchronized with the new technologies in order to remain flexible, efficient and integrated with partners, customers and suppliers. and all this in order to provide the industrial sector with greater profitability and quality at an acceptable and reduced cost, through the use of emerging technologies and concepts of Industry 4.0.

The Industry 4.0 consists of an "intelligence" where digital components are all interconnected with machines, tools, robots, men, finished and semi-finished products and raw materials in a single, fully integrated, flexible, independent and business-oriented network (Vuksanović, Ugarak, \& Korčok, 2016). In this context of disruptive industrial maintenance called Maintenance 4.0, the manufacturing process in the industries requires a greater attention in the predictive maintenance of machines with the advance of the technology and complexity of the components, in line with the continuous use of properties of the computers to control and monitor the properties dynamics of a physical good inside the factory (Pires, 2018). In order to maintain this industrial automation stable and with minimum risks, the architecture must be implemented in a continuous and fully integrated way, that does not divide the systems in isolation and without many hierarchical layers to avoid gaps and communication failures in the existents IS platforms in the corporate environment, as it is in some cases of traditional architectures in today's organizations (Saturno, Moura Pertel, Deschamps, \& De Freitas Rocha Loures, 2018).

Once this architecture is solved and the requirements necessary to implement new technologies related to Maintenance 4.0 are defined, several of these new technologies that can be implemented and adapted to the reality of the industry in order to obtain capital gains, better performance and quality in the manufacturing 
production process, in particular in the predictive analysis of machine failure (Scheer, 2015) (Algabroun, Iftikhar, Al-najjar, \& Weyns, 2017). This results in a series of systems to be parametrized and constantly regulated and which requires constant manual intervention in some of them due to the absence of a system or set of systems that self-regulates and able to deal with the variables of the business processes in the environment corporate. There is a constant concern to regulate properly for the current industrial model or any new model that is coupled to the existing one, this if the traditional model allows, which usually does not occur in this way.

In order to solve this problem, a new model of intelligent and completely self-sustaining architecture is proposed, based on Stafford Beer's Model of Viable Systems (MVS) (Espejo, Gill, \& Carvalho, 1997) that is flexible, adaptable and stable (Selin \& Santos, 2018). In addition, the VSM model is adapted with new emerging technologies in Maintenance 4.0 such as: data collection through sensors, mining and predictive analysis of this data, resulting in accurate automatic suggestions for replacement of industrial parts imminent to failure (Pires, 2018).

It is an autonomous and self-regulating system in terms of business rules, information and flow of processes existing in the organization and that, many of these processes and information outputs, would not require human intervention due to the prediction of patterns and data behavior of a given automation system (Selin \& Santos, 2018), thus allowing decision-making before failure in industrial machines for the context of Predictive Maintenance (Johnson, 2019).

For this automation process to be well defined, it is necessary first to classify and define a kind of taxonomy for each type of data and information generated in the business processes through the information flow of a factory. This process is achieved using injection techniques and data mining (using data obtained from the integration level of Information Systems to create plans and decision making (Crnjac, Veža, \& Banduka, 2017)), classifying this analytical and relevant information into categories of information related to the metrics and industrial equipment information (Qin, Liu, \& Grosvenor, 2016) (Chacada et al., 2018).

The present work proposes is a generic feasible system architecture for use in industry for M4.0 (Maintenance 4.0), where the implementation of this system (not covered by this work) will reduce the negative impacts on the industrial operation caused by manual configuration failures, machines (through predictive data analysis) and unstable integrations between subsystems, always synchronizing business flow with data flow more quickly and efficiently. Another motivating factor for this work was the search for a solution to the labor deficit in European industries in the face of the current situation of the population of European countries, where there is a high level of aging of the population and a significant technological competition of the industries with developing countries (Crnjac et al., 2017). With this, the proper use of the Cyber-Physical System, Internet of Things (IoT) and other disruptive technologies aimed at Maintenance 4.0 allows increasing the development of reducing the development time of products and the workforce needed for this production, optimizing manufacturing time, increasing production efficiency and providing cost reduction throughout the production process (Crnjac et al., 2017).

The result of the dissertation will be of great value for those who are interested in implementing autonomous solutions aimed at Maintenance 4.0, more precisely for those who want to obtain an architecture with visions of predictive data analysis in order to allow a preventive decision making in relation to the malfunction of industrial machines, if there is an imminence of failure.

\section{INDUSTRY AND MAINTENANCE 4.0}

\subsection{Concepts, History and Principles}

The core idea of Industry 4.0 is defined as a "smart" factory with all its networked components ranging from people to machines and products by flexible integration and integrate customers, partners, suppliers and products with efficiency. This model is always aimed at reducing costs, increasing performance and quality of production through automated processes (Vuksanović et al., 2016).

The history of the industrial revolution until the present times is subdivided in 4 stages (Vuksanović et al., 2016), as illustrated in figure 1. 


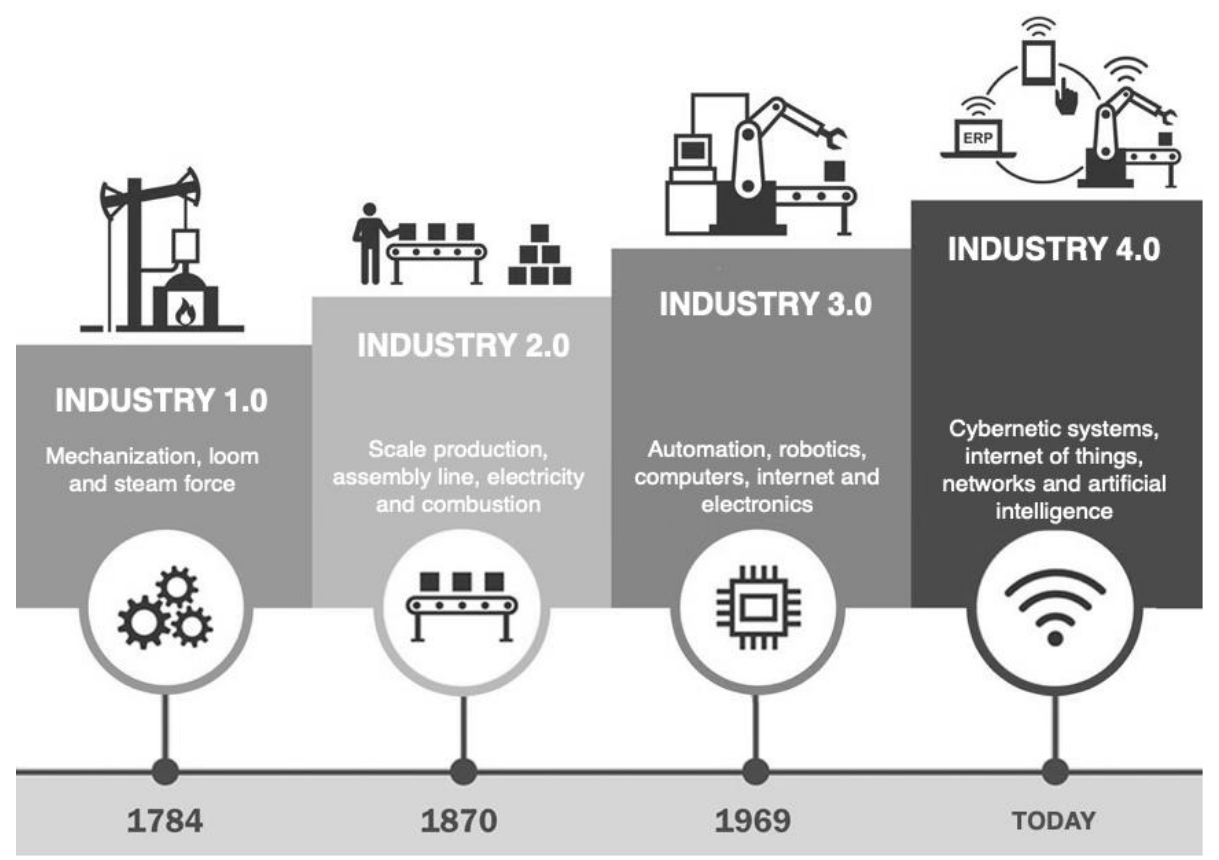

Figure 1. The 4 stages from the Industrial Revolution

(Adapted from: https://claudioperin.com.br/industria-4-0-qual-o-grau-de-maturidade-digital-da-sua-empresa/)

Still in the concept of interconnectivity, Table 1 illustrates the comparison of the use of Component, Machine and Production System in the current industries with technologies for Maintenance 4.0 with the concepts of I4.0, having as action the prevention and predictive analysis of these three elements mentioned.

Table 1. Comparison of today's factories with I4.0 factories

(Adapted from: https://www.researchgate.net/publication/303561107)

\begin{tabular}{|l|l|l|l|l|l|}
\hline \multirow{2}{*}{} & \multirow{2}{*}{ Data Source } & \multicolumn{2}{|c|}{ Today's industry } & \multicolumn{2}{c|}{ Industry 4.0 } \\
\cline { 3 - 6 } & & Attributes & Technologies & Attributes & Technologies \\
\hline Component & Sensor & Precision & $\begin{array}{l}\text { Smart Sensors \& } \\
\text { Fault Detection }\end{array}$ & $\begin{array}{l}\text { Self-aware } \\
\text { Self-predict }\end{array}$ & $\begin{array}{l}\text { Degradation } \\
\text { Monitoring \& } \\
\text { Remaining Useful } \\
\text { Life Prediction }\end{array}$ \\
\hline Machine & Controller & $\begin{array}{l}\text { Productivity } \\
\text { and } \\
\text { performance }\end{array}$ & $\begin{array}{l}\text { Condition-based } \\
\text { Monitoring \& } \\
\text { Diagnostics }\end{array}$ & $\begin{array}{l}\text { Self-aware } \\
\text { Self-predict } \\
\text { Self-compare }\end{array}$ & $\begin{array}{l}\text { Uptime with } \\
\text { Predictive Health } \\
\text { Monitoring }\end{array}$ \\
\hline $\begin{array}{l}\text { Production } \\
\text { System }\end{array}$ & Networking & $\begin{array}{l}\text { OEE } \\
\text { Productivity }\end{array}$ & $\begin{array}{l}\text { Lean Operations: } \\
\text { Work and Waste } \\
\text { Reduction }\end{array}$ & $\begin{array}{l}\text { Self-configure } \\
\text { Self-maintain } \\
\text { Self-organize }\end{array}$ & $\begin{array}{l}\text { Worry-free } \\
\text { Productivity }\end{array}$ \\
\hline
\end{tabular}

Industry 4.0 is believed to be the new Industrial Revolution of the 21 st century, as it allows for an autonomous vision and use of technology to produce services and products more intelligent, attractive, fast and flexible with the needs of today's market, always focusing on reduction of costs and increase in efficiency. On the other hand, there will be around 5 million types of jobs that could be extinguished due to this process of digitization in the main industrialized nations by 2020 (Vuksanović et al., 2016). Additionally, this is estimated to be a drastic reduction on demand for products where quality is doubtful and made by outdated technology, thus causing an outdated industry loss due to its inefficiency and high operating costs.

The design principles for Industry 4.0 are supported by 6 pillars that make up the technology for this new Era, which are (Horton, Prain, \& Thiele, 2015) presented in Table 2. 
Table 2. Design principles of each component from the Industry 4.0 (Adapted from:

https://www.researchgate.net/publication/307864150_Design_Principles_for_Industrie_40_Scenarios_A_Literature_Revi ew) (Horton et al., 2015)

\begin{tabular}{|l|c|c|c|c|}
\cline { 2 - 5 } \multicolumn{1}{c|}{} & Cyber-Physical & Internet of Things & Internet of Services & $\begin{array}{l}\text { Smart } \\
\text { Factory }\end{array}$ \\
\hline Interoperability & $\mathrm{X}$ & $\mathrm{X}$ & $\mathrm{X}$ & $\mathrm{X}$ \\
\hline Virtualization & $\mathrm{X}$ & - & - & $\mathrm{X}$ \\
\hline Decentralization & $\mathrm{X}$ & - & - & $\mathrm{X}$ \\
\hline Real-Time Capability & - & - & - & $\mathrm{X}$ \\
\hline Service Orientation & - & - & $\mathrm{X}$ & - \\
\hline Modularity & - & - & $\mathrm{X}$ & - \\
\hline
\end{tabular}

\subsection{Architectures for Maintenance 4.0: From Vision to Implementation}

Based on the concepts, principles and benefits of I4.0, we must think about the integration of all these components and information as a whole, thinking of an ideal architecture for a stable operation in a given IS, where its lack can lead to inconsistencies, risks of failures and, consequently, can lead to a total stop on an organization production day. In order to have a consistent and stable flow of information between different equipment and components in an automation solution, one must focus on new technologies focused on Maintenance 4.0 and forget the traditional models of automation that are based on the layered division, which can be a great bottleneck, as it creates isolated islands of Information Systems and obstacles that limit the access to some information of the system as a whole (Saturno et al., 2018).

To optimize industrial manufacturing processes through a new architecture that smartly uses the emerging new technologies in the market, a general analysis of the topology of the organization's current architecture is done, in order to identify the systems used, protocol types and the communication between them (Saturno et al., 2018). Then, it's verifies how adaptive the legacy systems are to receive the technologies offered and implemented in Maintenance 4.0, realizing their adherence and support with the new technologies.

Finally, the method called the Research Protocol Application (Saturno et al., 2018) is used, which consists of gathering information from the architecture across experts from each technological area, thus obtaining information from the current architecture topology in order to identify barriers, mitigate risks and impacts to receive the technologies coming from Maintenance 4.0.

Once identified the necessary requirements, solutions are researched to overcome these barriers and evolve to the implantation of these new technologies in the current platform of the organization.

Once the solution is designed to accept requirements of Maintenance 4.0, the organization analyzes the accepted components and selects the new technologies that would be of added value to the organization, with the aim of reducing costs, increasing performance and quality in production (Scheer, 2015).

One of the main components of a "Smart Factory" is the so-called Cyber-Physical Systems (commonly known as CPS), which consists of information systems for the intensive production chain, connected through the local network (or Internet) and capable of communicating with each other and also with other components equipped with the same "smart" communication technology through RFID or chip, where they carry their information of characteristics and qualities. Thus, the CPS allows the physical monitoring of objects and processes by creating a virtual simulation of the various elements of the physical world, thus decentralizing decision control with several autonomous devices (Pires, 2018).

It was also observed that the architectures of systems oriented to the industrial area should be focused on the product where, in addition, the logistics functions linked to the MES should have access to the characteristics and qualities of the product through the database (Scheer, 2015). This leads to another significant technology linked to Maintenance 4.0 for predictive analytics through a massive volume of data from the entire production process of the industry: the so-called Big Data (Scheer, 2015).

The implementation of such approaches requires a well-structured and driven architecture using the infrastructures of emerging Information and Communication Technologies (ICT) technologies and focused on the Maintenance 4.0. The ISO (International Standard Organization) defines a data communication standard for this type of systems architecture where the flow of this data begins at the top of the architecture where the monitoring configuration data is specified for the various sensors that monitor the equipment and, finally, result in actions to be taken by the maintenance and operations team. The figure 2 illustrates this data flow (Standard, Vibration, Standard, Cie, \& Standard, 2004). 


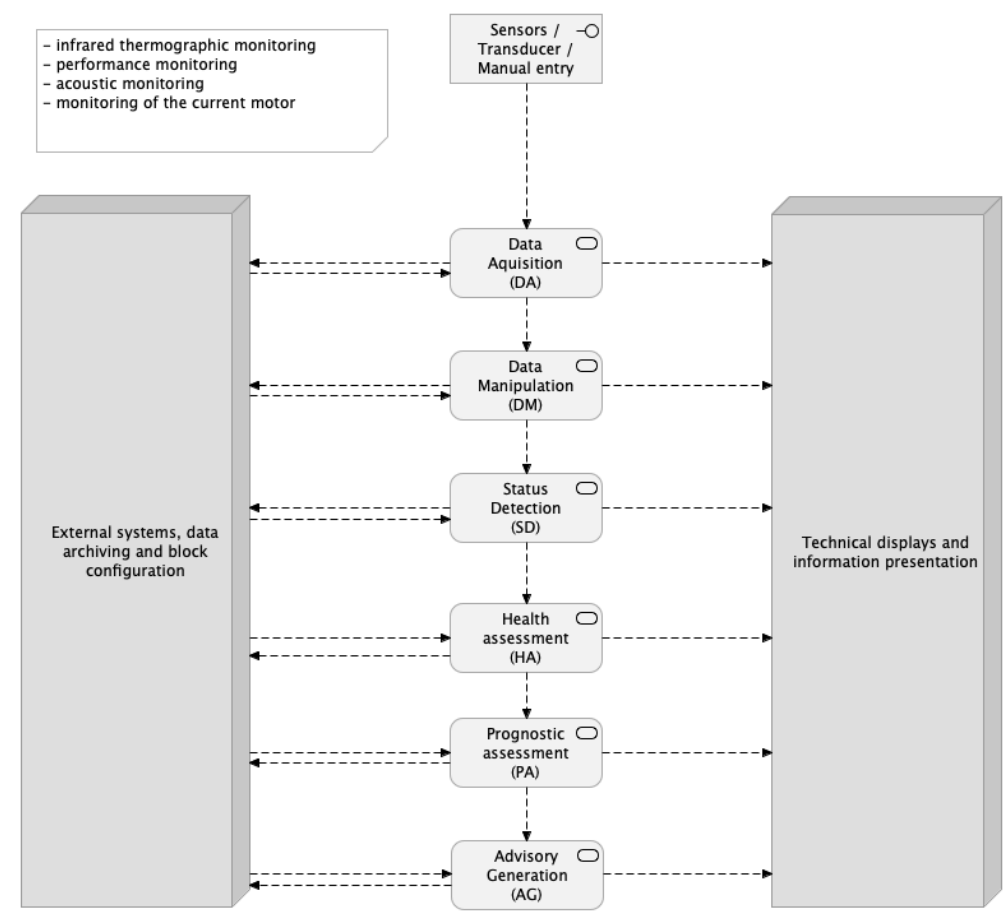

Figure 2. Data processing and information flow blocks (Adapted from: https://www.sis.se/api/document/preview/903685/)

In model above, the "Open System Architecture for Condition-Based Maintenance" (OSA-CBM) standard (Lopes, 2012) is used, where data collection, extraction and use comprise seven generic layers to achieve a well-constructed system of layers, but currently considers six functional blocks that are:

- Data Acquisition: provides access to scanned data from sensors or transducers and records this data;

- Data Manipulation: performs single and / or multichannel signal transformations and application of specialized resource extraction algorithms to the collected data;

- $\quad$ State Detection: performs condition monitoring by comparing features with expected values or operational limits and returning the condition and / or alarms indicator;

- Health assessment: determines if the health of the system is suffering from degradation, considering the trend in health history, operational status and maintenance history;

- Prognostic assessment: projects the current state of asset integrity in the future, considering an estimate of future usage profiles;

- Advisory Generation: Provides recommendations related to maintenance and asset configuration modification actions, considering operating history, current and future mission profiles, and resource constraints.

\subsection{Viable System Model adapted to Maintenance 4.0}

Given the hard maintenance of large corporate monolithic systems, where their complex parametrizations are manually adjusted daily (even in organizations that already use emerging ICT technologies), this systemic set becomes an easy target for a possible general bottleneck in its integrations, subsystems and adjustments. In addition, this chaotic scenario may reflect directly on the business, forcing it to stop for example a factory production and causing a huge financial loss if the failure is not detected timely.

Thus, it is proposed in (Selin \& Santos, 2018) a system model whose maintenance and adjustment is done automatically, by systems endowed with knowledge of the processes and information of an organization, through data mining and self-regulation of manufacturing systems configurations in accordance with the 
business model rules inserted (new or existing) in the context of the Corporate Information System in general or for part of a business process.

The proposed solution is to have an architecture adaptable to the reality of the factory production process, based on viable systems models (MSV) and using the new technologies related to Maintenance 4.0. The VSM (Viable System Model) acts in this context as an aid to the process of diagnosis and analysis of problems of the machines and/or equipment of the industry and to the process of organizational redesign in which the business models are aimed.

The model mentioned in (Selin \& Santos, 2018) consists of five main components (subsystems) for its operation, plus 2 more components adapted (proposed solution) with new technologies from Maintenance 4.0. The illustration of figure 3 shows how these components are interconnected:

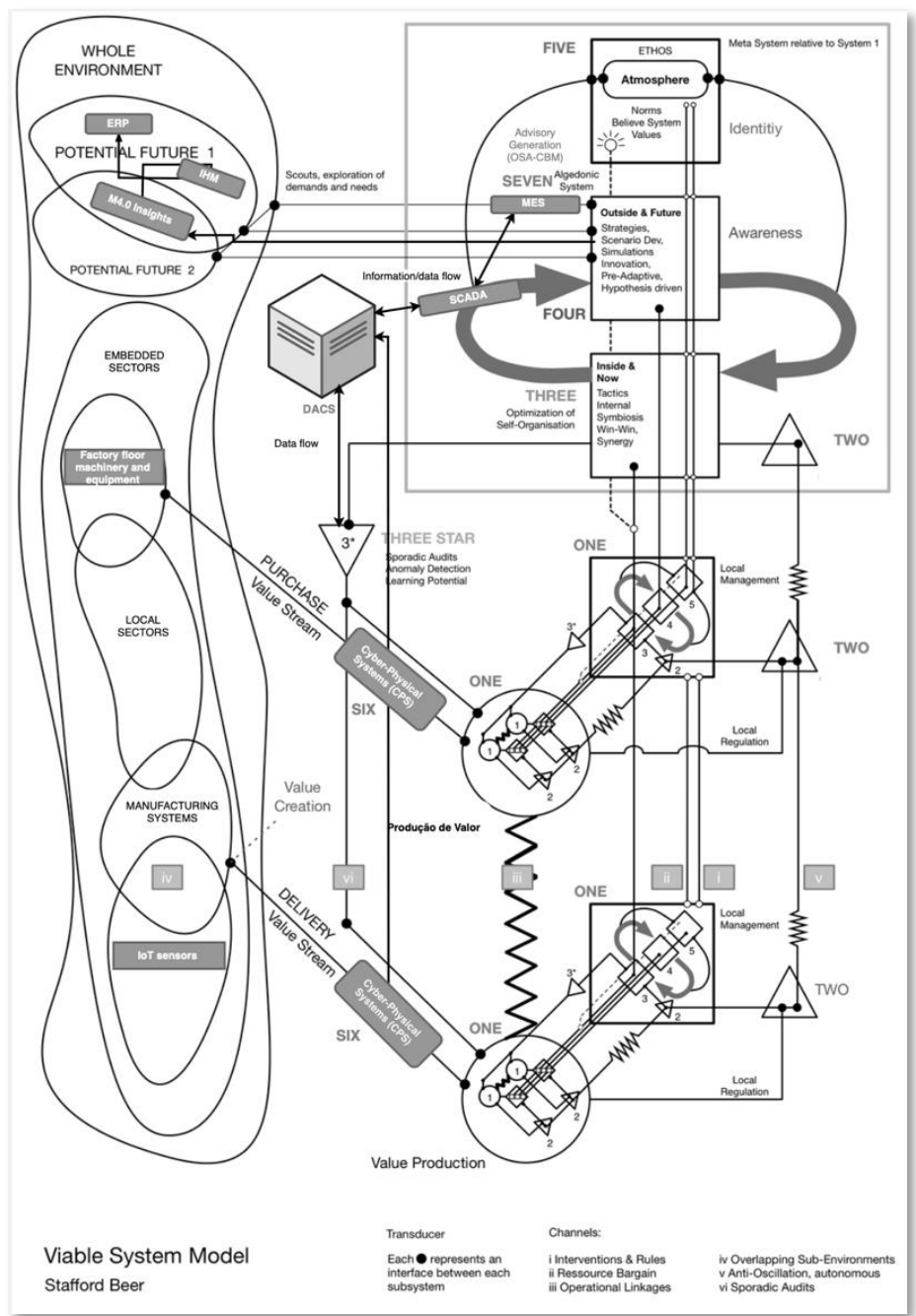

Figure 3. VSM architecture adapted for Maintenance 4.0

(Adapted from: http://www.ecotopia.com/images/vsmbig.gif)

As illustrated in the VSM model adapted in figure 3, the data flow to the generation of useful information for decision making follows:

a. The System 1 adapted to M4.0, different from the original VSM model that has just a operational systems collection, now receives (through the Cyber-Physical Systems - CPS) the data of operating machines, equipment and sensors that inform data about e.g. pressure, temperature, rotation and other data relevant for measuring the life of each essential equipment for a stable and optimized production; 
b. System 2 performs according to the original VSM, collecting and analyzing the raw data collected from the CPS through Systems 6 (Schütze, Helwig, \& Schneider, 2018) (Rossit, Tohmé, \& Frutos, 2018), recursively;

c. System 3 controls and sends audited data from System 2 to the DACS (Data Acquisition and Control Servers), where it will be stored in databases and controlled through data mining mechanisms;

d. System 4, through SCADA and MES systems, receives the data already treated for simulations and predictive analysis of algorithms from segmentation and data mining;

e. System 5 continues to operate according to the original Viable System Model, in constant search of anomalies according to pre-defined variables for the correct functioning of each equipment, thereby assisting System 7 for analysis and predictive cues;

f. System 7 suggests in the HMI (Machine Interface) panels (Johnson, 2019) the equipment exchange improvements to be replaced, showing the probability of failure in a short time;

g. The manufacturing area manager automatically receives a notification for purchase approval in the system that controls the purchase of parts of the industry (ERP system or other), with the model and the correct amount of equipment in the imminence of failures, suggested by System 7 (Lu, Riddick, \& Ivezic, 2016);

h. Once approved by the manufacturing manager, the purchase follows its internal flow normally for the replacement parts that have an almost exhausted useful life.

\section{CONCLUSION}

The main contribution of this work is the investigation of an ideal IS architecture for those industries that seek to innovate in the manufacturing sector of their organization, always having as information the ideal configurations (resilient to changes) and the monitoring of failures in the industrial environment by functions intelligent systems linked to autonomous systems through viable systems models.

In addition, the predictive analysis of the proposed model which is linked to the concepts and technologies offered in I4.0 through CPS and other emerging technologies, gives the manufacturing process more safety and fluidity without unexpected interruptions in the manufacturing of products by failure reasons of equipment or machine parts. This is thanks to this predictive and intelligent analysis carried out by the viable systems model adapted to the digital manufacturing (Cardoso \& Coradine, 2016) with Maintenance 4.0, which identifies the imminence of the occurrence of failures and suggests a purchase requisition with the damaged part / machine information.

The fact that we are going through an industrial revolution today, which is the 4th revolution or Industry 4.0 (Souza, 2018), makes implementations in this field still in an early stage in much of the world. With this, the exploitation of production technologies with information technologies is still maturing, and it is difficult to find jobs that are more focused on this area. There are many others issues related Maintenance 4.0 technologies that impacts negatively to improve theses implementations, such as (Liao, Wang, \& Lee, 2008):

- There is no variety of equipment level, and usually no infrastructure to cover these new technologies with a good performance;

- Doesn't exist a generic (and scalable) prognostic methodology, unless the companies use Cloud Computing for the entire productive process, but the trust on it is still rare;

- The degradation prediction tools and prognostics are poor and not trustable.

In summary, this suggested SI architecture will provide manufacturers with greater fluidity in the manufacturing process with the use of Maintenance 4.0 technologies discussed here (predictive and preventive analysis of machine data in imminent failures) and consequently a reduction of costs in the entire production system due to the constant automatic parametrization provided by the VSM. 


\section{REFERENCES}

Algabroun, H., Iftikhar, M. U., Al-najjar, B., \& Weyns, D. (2017). Maintenance 4 . 0 Framework Using Self- Adaptive Software Architecture. Proceedings of 2nd International Conference on Maintenance Engineering, IncoME-II 2017 The University of Manchester, UK, 1-11.

Cardoso, M., \& Coradine, R. (2016). Caminhos da Manufatura: Uma abordagem à Manufatura Digital (1. ${ }^{\mathrm{a}}$ ed.). São Paulo.

Chacada, A., Barbosa, J., Leitão, P., Geraldes, C. A. S., Deusado, L., Costa, J., ... Romero, L. (2018). Maintenance 4.0 - Intelligent and Predictive Maintenance System Architecture. Italy. https://doi.org/10.1109/ETFA.2018.8502489

Crnjac, M., Veža, I., \& Banduka, N. (2017). From concept to the introduction of industry 4.0. International Journal of Industrial Engineering and Management, 8(1), 21-30.

Espejo, R., Gill, A., \& Carvalho, J. Á. A. (1997). The viable system model as a framework for understanding organizations. Malhotra, Y. (Eds.), Knowledge Management and Virtual Organizations, Idea Group Publishing, 2000., (October 2011), 350-364. Retrieved from http://www.moderntimesworkplace.com/good_reading/GRRespSelf/TheViableSystemModel.pdf

Horton, D., Prain, G., \& Thiele, G. (2015). Design Principles for Industrie 4.0 Scenarios: A Literature Review. Social Sciences, (January). https://doi.org/10.13140/RG.2.2.29269.22248

Johnson, S. (2019). What Are the Advantages \&amp; Disadvantages of Hierarchical Structure? | Chron.com. Obtido 24 de Fevereiro de 2019, de https://smallbusiness.chron.com/advantages-disadvantages-hierarchical-structure-66002.html

Liao, L., Wang, H., \& Lee, J. (2008). A reconfigurable watchdog Agent ${ }^{\circledR}$ for machine health prognostics. International Journal of COMADEM, 11(3), 2-15. Retrieved from https://www.researchgate.net/publication/236891710

Lopes, Y. K. (2012). Integração dos Níveis MES, SCADA e Controle da Planta de Manufatura com Base na Teoria de Linguagens e Autômatos.

Lu, Y., Riddick, F., \& Ivezic, N. (2016). Advances in Production Management Systems. Initiatives for a Sustainable World (Vol. 488). https://doi.org/10.1007/978-3-319-51133-7

Pires, L. M. (2018). Manutenção na Indústria 4.0. Retrieved from https://www.researchgate.net/publication/329240288

Qin, J., Liu, Y., \& Grosvenor, R. (2016). A Categorical Framework of Manufacturing for Industry 4.0 and beyond. Procedia CIRP, 52, 173-178. https://doi.org/10.1016/j.procir.2016.08.005

Rossit, D. A., Tohmé, F., \& Frutos, M. (2018). Industry 4.0: Smart Scheduling. International Journal of Production Research, (November), 0-29. https://doi.org/10.1080/00207543.2018.1504248

Saturno, M., Moura Pertel, V., Deschamps, F., \& De Freitas Rocha Loures, E. (2018). Proposal of an Automation Solutions Architecture for Industry 4.0. Em DEStech Transactions on Engineering and Technology Research. https://doi.org/10.12783/dtetr/icpr2017/17675

Scheer, A. (2015). Whitepaper - Industry 4 . 0 : From vision to implementation, (September).

Schütze, A., Helwig, N., \& Schneider, T. (2018). Sensors 4.0 - Smart sensors and measurement technology enable Industry 4.0. Journal of Sensors and Sensor Systems, 7(1), 359-371. https://doi.org/10.5194/jsss-7-359-2018

Selin, A., \& Santos, V. (2018). An architecture for a viable information system. Advances in Intelligent Systems and Computing. https://doi.org/10.1007/978-3-319-77703-0_114

Souza, E. (2018). Entenda Sobre Indústria 4.0: A Quarta Revolução Industrial que estamos vivendo Hoje!

Standard, I., Vibration, M., Standard, I., Cie, S. E., \& Standard, I. (2004). International Standard (Vol. 2004). Retrieved from https://www.sis.se/api/document/preview/903685/

Vuksanović, D., Ugarak, J., \& Korčok, D. (2016). Industry 4.0: the Future Concepts and New Visions of Factory of the Future Development (pp. 293-298). https://doi.org/10.15308/sinteza-2016-293-298 